and relieving burdens placed on families who may be required to make future medical treatment decisions. Importantly ACP assists patients to communicate their future wishes to their family, and health care providers so that future medical care is consistent with their wishes.

Generally speaking ACP will commence with an individual reflecting on his or her values, beliefs, understanding his or her current and future treatment options determining their goals of care and discussing these with others, such as family and doctors. Often during the ACP process a person elects to appoint a substitute decision maker, and they may also decide to formally document their future treatment wishes. Ultimately for most people improving end-of-life care is a major goal and focus of ACP, and ensuring that the care received is consistent with previously expressed wishes is vital.

During this presentation I will review some measures which have been utilised to gauge the outcome of ACP at the various steps throughout the process as described above. I will also discuss other factors such as the quality of death and the impact the death on surviving relatives as other potentially important and measurable outcomes of ACP.

\title{
46 MEASURING SUCCESS IN ADVANCE CARE PLANNING. WHAT OUTCOMES ARE MEASURABLE, AND WHAT IS IMPORTANT?
}

K Detering ${ }^{1}$ Respecting Patient Choices, Austin Health, Australia

10.1136/bmjspcare-2012-000250.45

When considering the potential benefits of advance care planning (ACP) there are a number of factors that might be considered to be important. These may include preparation for possible future incapacity, preparation for end-o-life and death, 